\title{
Driving attitudes, behaviours, risk perception and risk concern among young student car-drivers, motorcyclists and pedestrians in various EU countries
}

\author{
Pierluigi Cordellieri $^{\mathrm{a}, *}$, Stefano Sdoia ${ }^{\mathrm{a}}$, Fabio Ferlazzo ${ }^{\mathrm{a}}$, Roberto Sgalla ${ }^{\mathrm{b}}$, Anna Maria Giannini ${ }^{\mathrm{a}}$ \\ a Department of Psychology, Sapienza University of Rome, Rome, Italy \\ ${ }^{\mathrm{b}}$ Department of Public Security, Italian Ministry of Internal Affairs, Rome, Italy
}

\section{A R T I C L E I N F O}

\section{Article history:}

Received 27 April 2018

Received in revised form 15 July 2019

Accepted 18 July 2019

\begin{abstract}
A B S T R A C T
The number of car crashes has gradually reduced in the last decade across all European Countries, but the number of motorcycle crashes has remained nearly the same. In our research we investigate whether there are differences in attitudes towards road safety issues, driving behaviours in specific imagined situations, risk perception and risk concern, among young student drivers and riders. The study involved a large sample taken from across six European countries.

The results reveal that although there are no differences between motorcyclists and car drivers in their attitudes toward road safety rules, differences do appear when the road rules compliance is assessed in specific imagined situations, with motorcyclists reporting to be more prone than car-drivers to violations of traffic rules. Moreover, despite the perceived risk during driving is the same for motorcyclists and car-drivers, differences do appear on their concern about this risk, with motorcyclists reporting to be less concerned than car-drivers about the risk of a road crash. This could lead to a high probability of risky driving behaviour in motorcyclists than in car-drivers. Present findings have important practical implications for road safety training courses.
\end{abstract}

(c) 2019 Elsevier Ltd. All rights reserved.

\section{Introduction}

Road safety is a high-priority issue for all the European countries, and many efforts have been made in the last decades to reduce the number of driving crashes. In 2001 most European countries agreed on the White Chart a policy document wherein the target of reducing by $50 \%$ the number of road crash deaths within one decade (from 54.000 in 2001 to 27.000 within 2010) was set. Some countries met reached this target in 2009 (such as Spain and Latvia, -52.8\% and $-54.5 \%$, respectively), and many others are gradually approaching it (e.g., Estonia and Portugal, with a $49.7 \%$ decrease in 2009 compared to 2001, as well as France and Lithuania with a $47.6 \%$ decrease). Thus, in the last decade road safety has overall improved slowly but steadily in Europe. However, road crashes remain an extremely severe problem. Besides the human tragedies road crashes cause, their cost for the EU countries was estimated at more than 160 billion euro per year, corresponding to 2\% of EU GNP, Gross National Product (EU road safety programme, 2003).

\footnotetext{
* Corresponding author at: Department of Psychology, Via dei Marsi, 78, 00185 Rome, Italy.

E-mail address: pierluigi.cordellieri@uniroma1.it (P. Cordellieri).
} 
Within this general picture, two aspects are especially important. The first is that young drivers are more frequently involved in road crashes than older drivers (OECD, Organisation for Economic Co-operationand and Development, 2006; Subramanian, 2006; World Health Organization (WHO) (2004), 2004). Road crashes are indeed the major cause of death among young people, with the most vulnerable group being represented by people between 15 and 29 years. The second is that, despite the overall strong decrease in the number of road crashes, motorcyclists' fatalities decrease much more slowly. Actually, during the last decade (from 2006 to 2015), the European countries have seen a strong decrease of fatalities for traffic accident ( $-45 \%$ fatalities for drivers or passengers of cars and taxis; $-57 \%$ fatalities for driver of heavy goods vehicles $>3,5$ t; Source: CARE-EU road accidents database, 2017). For motorcyclists, the number of fatalities decreased by only 28\%. Motorcycle and moped (together referred to as Powered Two Wheelers - PTW) road fatalities accounted for $18 \%$ of the total number of road crash fatalities occurred in 2015 in the EU-28 countries.

Thus, the number of car crashes has been gradually decreasing in the last decade, whereas the number of PTW crashes has slightly increased.

The reasons for such a discrepancy are still unclear; though, understanding this phenomenon is necessary for any crashes prevention programs to be effective. The purpose of the present study is to investigate whether a difference does exist in the general attitude toward road-safety issues between car-drivers and PTW riders that can account for the discrepancy in the number of road crashes between these two groups of road users. The study starts up within the European Commission's ICARUS project (Inter-Cultural Approaches for Road Users Safety) which focused on the behaviours of young drivers as well as on the main factors jeopardizing road safety.

The high crash rates shown by PTW riders is generally considered a consequence of several factors, spanning from the higher vulnerability of motorcycles from road risks to the riders' driving attitudes and behaviours (e.g., Elliott, Baughan, \& Sexton, 2007; Cheng, Ng, \& Lee, 2011). For example, Mannering and Grodsky (1995) described different reasons that cause a greater exposure of motorcyclists to road crashes. First, car-drivers tend to be inattentive toward motorcyclists, paying more attention to other cars. Second, riding a motorcycle is a very complex task, even more complex than driving a car, that requires motor skills and physical coordination, and often has to be performed with concurrent tasks (Walker et al., 2006, 2007). Crash risk has also been found to be significantly correlated with some motorcyclists' individual characteristics, such as the riding experience (Savolainen \& Mannering, 2007; Sexton, Baughan, Elliot, \& Maycock, 2004), the riding exposure (Lin, Chang, Pai, \& Keyl, 2003; Mannering \& Grodsky, 1995), the rider age (Harrison \& Christie, 2005) and sex (Lin et al., 2003; Mannering \& Grodsky, 1995) and the engine capacity (Harrison \& Christie, 2005). The young age is generally associated with a higher risk to incur in road crashes, together with riding too fast (e.g., Carroll \& Waller, 1980; Lin et al., 2003; Wells, 1986), drink-riding (e.g., Fell \& Nash, 1989; Lin et al., 2003) and poor observation and signalling at junctions (e.g., Wells, 1986). Interestingly, whereas driving attitudes have since long been shown to play an important role in road crashes (e.g., Rolls \& Ingham, 1992; West \& Hall, 1997; Parker \& Manstead, 1996; Parker, Lajunen, \& Strandling, 1998), only few studies directly investigated the motorcyclists' attitudes toward road safety issues (e.g., Elliott, 2010; Hosking, Liu, \& Bayly, 2010; Chorlton, Conner, \& Jamson, 2012; Özkan, Lajunen, Dogruyol, Yildirim, \& Coymak, 2012; Tunnicliff et al., 2012). However, most of them did not compare the driving attitudes of PTW riders, car-drivers, and non-drivers, but mostly focused upon specific countries.

The present study aims at investigating whether differences in road safety attitudes, driving behaviour and risk perception do exist among young car-drivers, motorcyclists and non-drivers that can account for the high crash rates of motorcyclists compared to car-drivers. Notably, such an issue has been here explored in a large sample of participants, selected from six different European countries. Both the general attitudes toward road safety issues and the driving behaviour in specific imagined situations were assessed. These measures were based on the idea that although both motorcyclists and car-drivers can show a high compliance to road rules as a general attitude toward road safety issues (Horswill \& Helman, 2003), they can still differ in rules compliance (e.g., violations) when required to imagine themselves in specific driving situations. Such a hypothesis stems from the person-situation interaction theoretical framework (e.g., Cervone and Shoda, 1999), wherein the idea that the situation plays a more influential role than personality traits do in determining a person's behaviour, has been progressively developed.

Furthermore, the risk-taking behaviour of motorcyclists is unlikely to account completely for the difference in crash risk between motorcyclists and car drivers (Horswill \& Helman, 2003). Therefore, we hypothesized that, although motorcyclists and car-drivers can be similar in terms of perceived risk of being involved in crashes due to violations of road rules, they could still differ in terms of worry about this risk. The distinction is that worry has been described as an emotional response to a threat, whereas perceived risk has been described as a cognitive judgment (Sjöberg, 1998). Recently, there has been a growing interest in affect, rather than cognitive judgement, as a predictor of behaviour and decision making (Chapman \& Coups, 2006; Loewenstein, Weber, Hsee, \& Welch, 2001; Slovic, Peters, Finucane, \& MacGregor, 2005) and it has been shown that worry plays an important role in influencing people's decision (Schmiege, Klein, \& Bryan, 2009). For example, the effect of worry has been examined across a number of health contexts and a positive correlation has been frequently observed between worry and health-protective behaviour (McCaul \& Mullens, 2003). Despite some existing evidence that worry and risk are modestly correlated with one another (e.g., Collins, Halliday, Warren, \& Williamson, 2000; Easterling \& Leventhal, 1989; Sjöberg, 1998), the moderate size of these correlations suggests that they are also conceptually different psychological variables. On these grounds, the crash risk perception and the concern about this risk were both assessed in the present study. 


\section{Material and methods}

\subsection{Participants}

A preliminary sample of 6081 young individuals from Italy, Austria, Bulgaria, Lithuania, Poland and Slovenia participated in the study (age range 19-22). Participants were recruited from schools and universities that had been preliminarily selected in a random manner from each different country according to different demographic districts. Classes from schools and courses from universities were then randomly selected from each institute and pupils agreed or disagreed to participate.

According to the reported personal driving experience, each participant was assigned to one of three different groups: Car-drivers (participants who usually drive a car, even if they also occasionally ride a PTW), Motorcyclists (participants who usually ride a PTW, but not a car) and Non-drivers (participants who drive neither a car nor a PTW). Participants who had been involved crashed were not included in the sample. Since motorcyclists were under-represented in the general sample, a few car-drivers and non-drivers participants were randomly removed from the preliminary national samples in order to get a more balanced sample size across the three groups for each country, with a total number of 4673 participants remaining from the six European countries, distributed in 1781 Car-drivers, 1236 Motorcyclists and 1656 Non-drivers (Table 1). Drivers and riders answered a few questions to verify their level of driving expertise (Tables 2-4). The study was performed according to the ethical principles expressed in the Declaration of Helsinki.

\subsection{Materials and procedures}

Participants were required to fill in a questionnaire asking for basic demographic information and driving records, including an estimation of how many kilometres they usually drive weekly. The questionnaire was aimed at assessing the attitudes

Table 1

Number of participants involved in the study separated for the six different European Country and type of road user.

\begin{tabular}{|c|c|c|c|c|c|c|c|}
\hline \multirow[t]{2}{*}{ Country } & \multicolumn{2}{|c|}{ Car drivers } & \multicolumn{2}{|c|}{ Motorcyclists } & \multicolumn{2}{|c|}{ Non drivers } & \multirow[t]{2}{*}{$\mathrm{N}$} \\
\hline & Males & Females & Males & Females & Males & Females & \\
\hline \multirow[t]{2}{*}{ Austria } & 139 & 115 & 109 & 42 & 133 & 119 & 657 \\
\hline & $13.0 \%$ & $16.1 \%$ & $13.7 \%$ & $9.6 \%$ & $15.0 \%$ & $15.5 \%$ & $14.1 \%$ \\
\hline \multirow[t]{2}{*}{ Bulgaria } & 259 & 41 & 140 & 21 & 234 & 73 & 768 \\
\hline & $24.3 \%$ & $5.8 \%$ & $17.6 \%$ & $4.8 \%$ & $26.4 \%$ & $9.5 \%$ & $16.4 \%$ \\
\hline \multirow[t]{2}{*}{ Italy } & 236 & 158 & 239 & 107 & 147 & 205 & 1092 \\
\hline & $22.1 \%$ & $22.2 \%$ & $30.0 \%$ & $24.4 \%$ & $16.6 \%$ & $26.7 \%$ & $23.4 \%$ \\
\hline \multirow[t]{2}{*}{ Lithuania } & 127 & 135 & 155 & 76 & 81 & 144 & 718 \\
\hline & $11.9 \%$ & $18.9 \%$ & $19.4 \%$ & $17.3 \%$ & $9.1 \%$ & $18.8 \%$ & $15.4 \%$ \\
\hline \multirow[t]{2}{*}{ Poland } & 176 & 95 & 107 & 52 & 114 & 102 & 646 \\
\hline & $16.5 \%$ & $13.3 \%$ & $13.4 \%$ & $11.8 \%$ & $12.8 \%$ & $13.3 \%$ & $13.8 \%$ \\
\hline \multirow[t]{2}{*}{ Slovenia } & 131 & 169 & 47 & 141 & 179 & 125 & 792 \\
\hline & $12.3 \%$ & $23.7 \%$ & $5.9 \%$ & $32.1 \%$ & $20.2 \%$ & $16.3 \%$ & $16.9 \%$ \\
\hline $\mathrm{N}$ & 1068 & 713 & 797 & 439 & 888 & 768 & 4673 \\
\hline
\end{tabular}

Table 2

Driving habits 1 . Frequency distribution of respondents for item "How many times a week do you use the car? Thinking of the last three months".

\begin{tabular}{|c|c|c|c|c|c|c|}
\hline & \multicolumn{6}{|c|}{ How many times a week do you use the car/motorbike? ${ }^{a}$} \\
\hline & Never & $1-2$ times & $3-4$ times & $5-6$ times & Every day & Only in the weekend \\
\hline \multicolumn{7}{|l|}{ Driver } \\
\hline Bulgaria & $3.0 \%$ & $17.9 \%$ & $17.9 \%$ & $14.9 \%$ & $46.3 \%$ & $0 \%$ \\
\hline Italy & $0 \%$ & $7.6 \%$ & $16.7 \%$ & $14.9 \%$ & $59.0 \%$ & $1.8 \%$ \\
\hline Lithuania & $0.7 \%$ & $11.3 \%$ & $19.9 \%$ & $24.8 \%$ & $41.8 \%$ & $1.4 \%$ \\
\hline Poland & $0 \%$ & $8.1 \%$ & $20.7 \%$ & $15.7 \%$ & $52.5 \%$ & $3.0 \%$ \\
\hline Slovenia & $2.1 \%$ & $18.5 \%$ & $21.7 \%$ & $15.4 \%$ & $38.1 \%$ & $4.2 \%$ \\
\hline \multicolumn{7}{|l|}{ Riders } \\
\hline Austria & $4.3 \%$ & $14.5 \%$ & $26.8 \%$ & $18.1 \%$ & $29.7 \%$ & $6.5 \%$ \\
\hline Bulgaria & $4.0 \%$ & $22.2 \%$ & $20.6 \%$ & $15.9 \%$ & $29.4 \%$ & $7.9 \%$ \\
\hline Italy & $9.0 \%$ & $20.0 \%$ & $20.7 \%$ & $17.6 \%$ & $31.4 \%$ & $1.4 \%$ \\
\hline Lithuania & $4.6 \%$ & $30.9 \%$ & $27.8 \%$ & $11.9 \%$ & $18.6 \%$ & $6.2 \%$ \\
\hline Poland & $6.0 \%$ & $32.8 \%$ & $20.9 \%$ & $11.2 \%$ & $23.9 \%$ & $5.2 \%$ \\
\hline Slovenia & $6.2 \%$ & $24.4 \%$ & $26.7 \%$ & $18.2 \%$ & $17.0 \%$ & $7.4 \%$ \\
\hline
\end{tabular}

a Several data are missing for this item. 
Table 3

Driving habits 2. Frequency distribution of respondents for item "How many Kilometers do you drive in a week?".

\begin{tabular}{|c|c|c|c|c|c|}
\hline & \multicolumn{5}{|c|}{ How many Kilometers do you drive in a week ${ }^{\mathrm{a}}$} \\
\hline & $1-10 \mathrm{~km}$ & $11-30 \mathrm{~km}$ & $31-50 \mathrm{~km}$ & $51-100 \mathrm{~km}$ & More than $100 \mathrm{Km}$ \\
\hline \multicolumn{6}{|l|}{ Driver } \\
\hline Austria & $3.4 \%$ & $9.1 \%$ & $21.1 \%$ & $20.6 \%$ & $45.7 \%$ \\
\hline Bulgaria & $9.7 \%$ & $15.7 \%$ & $17.9 \%$ & $23.9 \%$ & $32.8 \%$ \\
\hline Italy & $4.6 \%$ & $13.1 \%$ & $23.1 \%$ & $25.2 \%$ & $34.0 \%$ \\
\hline Lithuania & $0.7 \%$ & $9.9 \%$ & $18.4 \%$ & $47.5 \%$ & $23.4 \%$ \\
\hline Poland & $2.5 \%$ & $8.1 \%$ & $16.7 \%$ & $21.7 \%$ & $51.0 \%$ \\
\hline Slovenia & $7.0 \%$ & $17.5 \%$ & $25.9 \%$ & $19.6 \%$ & $30.1 \%$ \\
\hline \multicolumn{6}{|l|}{ Riders } \\
\hline Austria & $18.8 \%$ & $31.2 \%$ & $18.8 \%$ & $17.4 \%$ & $13.8 \%$ \\
\hline Bulgaria & $15.1 \%$ & $18.3 \%$ & $22.2 \%$ & $23.0 \%$ & $21.4 \%$ \\
\hline Italy & $22.4 \%$ & $23.8 \%$ & $22.8 \%$ & $19.0 \%$ & $12.1 \%$ \\
\hline Lithuania & $9.3 \%$ & $21.6 \%$ & $34.0 \%$ & $27.3 \%$ & $7.7 \%$ \\
\hline Poland & $18.7 \%$ & $21.6 \%$ & $14.9 \%$ & $19.4 \%$ & $25.4 \%$ \\
\hline Slovenia & $21.1 \%$ & $24.0 \%$ & $22.9 \%$ & $18.9 \%$ & $13.1 \%$ \\
\hline
\end{tabular}

a Several data are missing for this item.

Table 4

Driving habits 3. Frequency distribution of respondents for item "In the last three months, how many times have you driven after 11.00 pm?".

\begin{tabular}{|c|c|c|c|c|}
\hline & \multicolumn{4}{|c|}{ In the last three months. How many times have you driven after $11.00 \mathrm{pm} ?^{\mathrm{a}}$} \\
\hline & Never & $1-2$ times & 3-4 times & More than 4 times \\
\hline \multicolumn{5}{|l|}{ Drivers } \\
\hline Austria & $24.0 \%$ & $26.9 \%$ & $22.3 \%$ & $26.9 \%$ \\
\hline Bulgaria & $33.6 \%$ & $29.1 \%$ & $19.4 \%$ & $17.9 \%$ \\
\hline Italy & $28.0 \%$ & $16.4 \%$ & $19.8 \%$ & $35.9 \%$ \\
\hline Lithuania & $36.9 \%$ & $14.9 \%$ & $17.7 \%$ & $30.5 \%$ \\
\hline Poland & $23.2 \%$ & $35.4 \%$ & $16.2 \%$ & $25.3 \%$ \\
\hline Slovenia & $40.7 \%$ & $27.4 \%$ & $19.0 \%$ & $12.9 \%$ \\
\hline \multicolumn{5}{|l|}{ Riders } \\
\hline Austria & $34.8 \%$ & $28.3 \%$ & $13.0 \%$ & $23.9 \%$ \\
\hline Bulgaria & $31.0 \%$ & $24.6 \%$ & $21.4 \%$ & $23.0 \%$ \\
\hline Italy & $39.3 \%$ & $22.8 \%$ & $10.3 \%$ & $27.6 \%$ \\
\hline Lithuania & $35.1 \%$ & $24.7 \%$ & $11.9 \%$ & $28.4 \%$ \\
\hline Poland & $40.3 \%$ & $27.6 \%$ & $13.4 \%$ & $18.7 \%$ \\
\hline Slovenia & $41.1 \%$ & $33.1 \%$ & $12.6 \%$ & $13.1 \%$ \\
\hline
\end{tabular}

a Several data are missing for this item.

toward road safety issues, the driving behaviours in specific hypothetical situations, the crash risk perception, and the concern about such a risk. The questionnaire contained the following measures:

\subsubsection{Attitude toward road-safety issues (Driving attitudes scale - DAS - Iversen E Rundmo, 2004)}

The scale assesses the road-safety attitudes related to driving. Specifically, the attitudes towards rule violations and speeding, careless driving, as well as the attitude toward driving under the effects of alcohol and drugs were assessed (e.g., "Speed limit cannot be observed because it is too restrictive"). All the items were answered on six-point response scales ranging from "strongly disagree" (0) to "strongly agree"(5), with high scores indicating a negative attitude towards traffic safety (i.e., high preferences for risk-taking behaviour).

\subsubsection{Driving behaviour (Imagined Driving Behaviour Scale - IDBS)}

This scale was derived from the Driver Behaviour Questionnaire (DBQ, Reason, Manstead, Stradling, \& Baxter, 1990), which has become one of the most widely used scales for assessing the self-reported driving behaviours (Lajunen, Parker, \& Summala, 2004). The IDBS aims at assessing the driving behaviour in a specific hypothetical situation (being late for a visit to a friends' place). Respondents are required to indicate, on a six point scale ranging from "most unlikely" (0) to "most likely" (5), how likely they think they would perform the behaviour described in the items (e.g., "You drive without keeping a safe distance").

\subsubsection{Crash risk perception}

Two items measuring risk perception were also included. On a ten point response scale, ranging from "very low" (1) to "very high" (10), respondents were asked to evaluate their likelihood of being involved in a car crash compared to their 
fellows (i.e., "If you drive a car, how would you assess your risk of having a road crash as against the persons of your age?") and to indicate their level of concern about this possibility (i.e., "How much are you worried about this possibility?").

The scales were almost identical for the three groups of car-drivers, motorcyclists and non-drivers, with the exception that items were adapted for the specific group of respondents.

\subsection{Statistical analyses}

Data from the Driving Attitude Scale and Imagined Driving Behaviour Scale were separately submitted to exploratory factor analyses, using the Principal Axis method and the oblique Oblimin rotation. Factor scores were then computed through the regression method for each factor, and used for further statistical analyses. Specifically, in order to examine possible differences between groups in the driving attitudes and imagined driving behaviour, factor scores from the two scales (Attitudes and Behaviours) were separately submitted to an Analysis of Variance (ANOVA) with Group (Car-drivers, Motorcyclists and Non-drivers) and Factors of each scale as independent variables. In order to examine possible differences between groups in risk perception and level of concern about this risk, the scores from the two Crash Risk Perception items (Personal Crash probability and Level of concern) were also submitted to a 3 (Car-drivers, Motorcyclists and Non-drivers) $\times 2$ (Crash Probability and Concern) ANOVA.

\section{Results}

\subsection{Factor analysis}

\subsubsection{Attitude toward road safety issues}

Data from the Driving Attitudes Scale were submitted to exploratory factor analysis (Principal Axis method, Oblimin rotation). Measures of sampling adequacy (Kaiser-Meyer-Olkin $=0.861$ ) and factorability of the correlation matrix (Bartlett's test of sphericity $\left.\chi^{2}(153)=23261.63, \mathrm{p}<0.0001\right)$ were both adequate. The scree-test yielded a four-factor solution accounting for the $52.7 \%$ of the total variance. The first factor, labelled "Risky driving", accounts for the $16.76 \%$ of the common variance and refers to the positive attitude toward risky driving behaviours. Items such as "High-speed driving is possible if road conditions are good and there is nobody around" load on this factor.

The second factor, labelled "Negative attitude towards drugs and alcohol", accounts for the $17.07 \%$ of the common variance and refers to the negative attitude toward driving under the effects of psychoactive substances. Items such as "I would never drive after drinking alcoholic drinks" and "I would never drive under the influence of narcotic drugs" load on this factor. The third factor, labelled "Tolerance toward speeding", accounts for the $10.43 \%$ of the common variance and refers to a positive attitude toward going by car with a fast driver. Items such as "It is ok to go by car with a fast driver if it is the only way to go back home at night" load on this factor. This factor shows a slight positive correlation with the first factor (0.38). The fourth factor, labelled "Negative attitude toward traffic rules", accounts for the $15.44 \%$ of the common variance and refers to a negative attitude toward traffic rules. Items such as "To keep traffic smooth-flowing you should ignore many of the road traffic rules" load on this factor. This factor positively correlates with the first factor $(0.65)$.

The four factors of the DAS have excellent internal consistency (Cronbach's index $=0.70-0.84$; precisely: First factor $\alpha=0.74$; Second factor $\alpha=0.84$; Third factor $\alpha=0.71$; Fourth factor $\alpha=0.70$ )

\subsubsection{Imagined driving behaviour}

Data from the Imagined Driving Behaviour Scale were submitted to exploratory factor analysis (Principal Axis method, Oblimin rotation). Measures of sampling adequacy (Kaiser-Meyer-Olkin $=0.889$ ), and factorability of the correlation matrix (Bartlett's test of sphericity $\chi^{2}(153)=38558.926, \mathrm{p}<0.0001$ ) were both adequate. The scree-test yielded a four-factor solution accounting for the $57.14 \%$ of the total variance. The first factor, labelled "Risky and inattentive driving", accounts for by the $17.64 \%$ of the common variance and refers to driving without respecting and paying attention to road rules. Items such as "To drive without keeping a safe distance" load on this factor. The second factor, labelled "Cautious driving", accounts for by the $13.89 \%$ of the common variance and especially refers to slowing when needed. Items such as "You slow down in case of bad conditions (road, weather, etc,) even if you are driving within the speed limit" load on this factor. The third factor, labelled "Positive attitude toward traffic rules", accounts for by the $17.54 \%$ of the common variance and refers to complying with the traffic rules. Item such as "You exceed the speed limit by $10 \mathrm{Km} / \mathrm{h}$ " negatively load on this factor. The fourth factor, labelled "Driving under the effects of alcohol and drugs", accounts for by the $17.12 \%$ of the common variance and refers to a positive attitude toward driving under the influence of psycho-active substances. Items such as "You drive after having drunk, even though you are not sure you have sobered up" load on this factor. This factor positively correlates with the first one (0.58).

The four factors of the IDBS have excellent internal consistency (Cronbach's index $=0.78-0.86$; precisely: First factor $\alpha=0.81$; Second factor $\alpha=0.82$; Third factor $\alpha=0.86$; Fourth factor $\alpha=0.78$ )

Notably, in order to rule out the possibility that results might be biased by having considered Likert scales as they were metric measures, we repeated the analyses using polychoric correlations (Polycor package in R, Fox, 2013, two-step procedure) instead of Pearson's (e.g., Foreo, Maydeu-Olivares, \& Gallardo-Pujol, 2009). The results were virtually identical to those 
reported, with the same factor structure emerging from the analyses on the "Attitude toward road safety issues" and on the "Imagined driving behavior".

\subsection{ANOVA results}

\subsubsection{Attitude toward road safety issues}

Factor scores from the four components of the Driving Attitudes Scale were submitted to a 3x2x4 Factorial ANOVA mixed design with Group (Car-drivers, Motorcyclists and Non-drivers) and Gender (Female and Male) as between factors, and DAS components (Risky driving; Negative attitude toward drugs and alcohol; Tolerance toward speeding, Negative attitude toward traffic rules) as repeated measures. We included the gender variable to verify the effects of the interaction gender X Group. We wanted to control the gender factor.

The ANOVA revealed a significant Group X Component interaction $[\mathrm{F}(6,13470)=3.53 ; \mathrm{p}<.01]$ (Fig. 1 and Table 5), and a significant Gender X Component interaction $([F(3,13470)=67.67 ; \mathrm{p}<.001]$ (Fig. 2 and Table 6), but the interaction Group X Gender was not significant $([\mathrm{F}(6,13470)=1.331 ; \mathrm{p}=.239]$. Therefore, we can exclude an influence of the gender variable on the group outputs. Planned comparisons for Group revealed that non drivers participants had higher scores on the Negative attitude toward Alcohol and Drugs component $[\mathrm{F}(1,4498)=5.43, \mathrm{p}<.02]$ and lower scores on the Negative attitude toward traffic rules component $[\mathrm{F}(1,4498)=16.31, \mathrm{p}<.001]$ than both car and motorcycle riders. Also, motorcycle riders had higher scores on the Tolerance toward speeding component than car drivers $[F(1,4498)=6.39, p<.02]$. The three groups did not differ in any other component ( $\mathrm{p}>.05$ in all cases). These results suggest that motorcyclists are more prone to speeding than car drivers, while there are no differences between these two groups in the other attitudes (see Fig. 3).

Comparisons for Gender revealed different effects for all DAS components. Precisely, females showed lower scores on Risky driving $[\mathrm{F}(1,4494)=21.76, \mathrm{p}<.001]$, Tolerance toward speeding $[\mathrm{F}(1,4494)=36.96, \mathrm{p}<.001]$, and Negative attitude toward traffic rules $[F(1,4494)=93.29, \mathrm{p}<.001]$, but higher scores on Negative attitude toward drugs and alcohol $[\mathrm{F}(1,4494)=76.98, \mathrm{p}<.001]$.

\subsubsection{Imagined driving behaviour}

To investigate possible differences among groups in driving behaviour as assessed in specific hypothetical situations, factor scores from the components derived from the factorial analysis of the Imagined Driving Behaviour Scale were submitted to a 3x2x4 ANOVA mixed design, with Group (Car-drivers, Motorcyclists and Non-drivers) and Gender (Female and Male) as between factors, and IDBS Components (Risky and inattentive driving, Cautious driving, Positive attitude toward traffic code, and Positive attitude toward Drugs \&alcohol) as repeated measures. By including the gender variable, we wanted to verify the interaction with the group variable. Besides the significant main effect of the Group (which has no interest as it represents the overall scores mean of the four factors for each group), the ANOVA revealed a significant Group X Components

\section{GENERAL ATTITUDES}

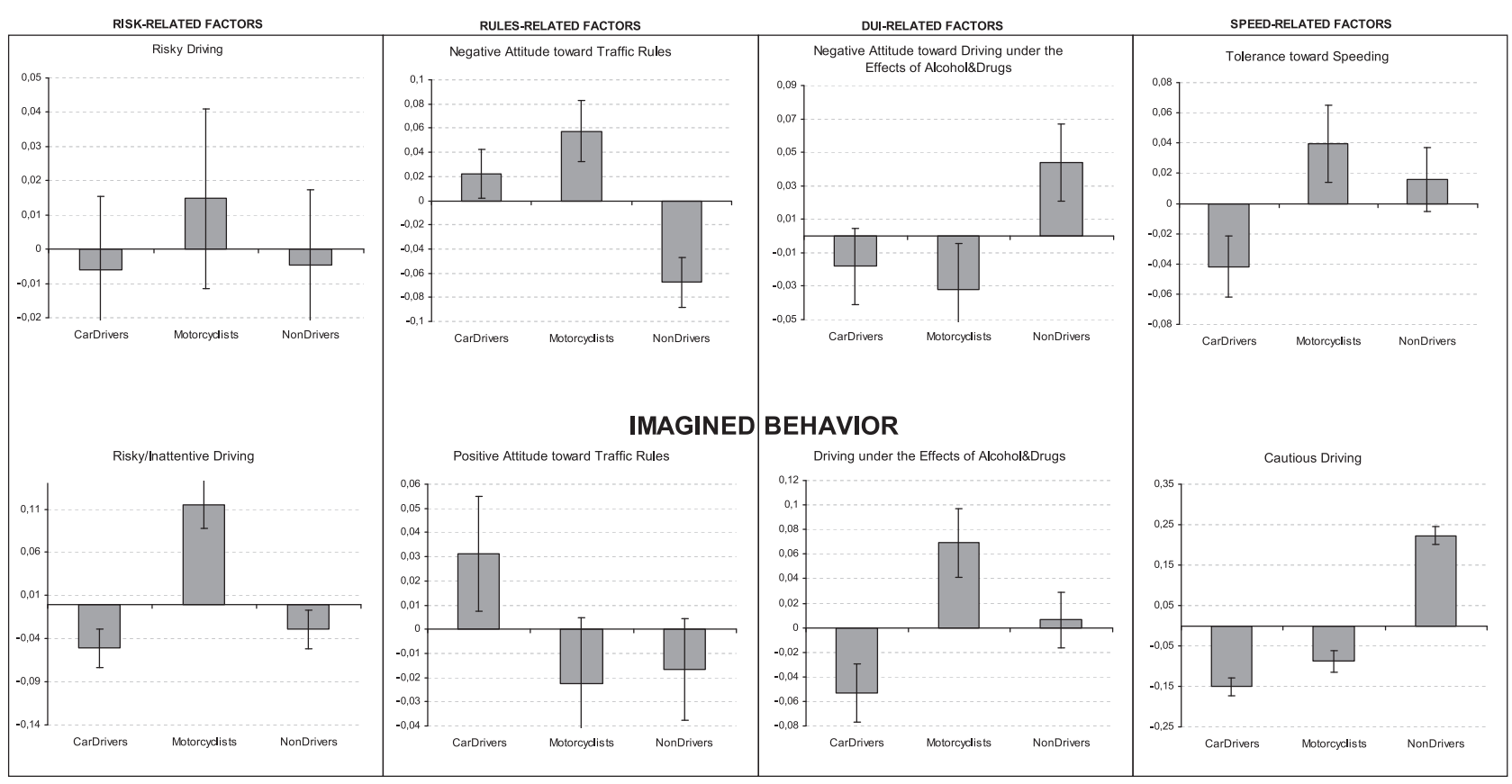

Fig. 1. Mean factor scores for the four dimensions (Risk-, Rules-, DUI-, and Speed-related factors) derived from both the Attitudes and the Imagined Behaviours Scales are represented for each group of road users (car drivers, motorcyclists and non-drivers). 
Table 5

Mean factor scores for the four dimensions (Risk, Rules, DUI, and Speed) of the Attitudes and the Imagined Behaviours Scales are represented for each group of road users (car drivers, motorcyclists and non-drivers). Standard errors are reported in brackets.

\begin{tabular}{|c|c|c|c|c|c|c|c|c|c|c|}
\hline & & \multirow[t]{2}{*}{ Measure } & \multirow[t]{2}{*}{ Group } & \multirow[t]{2}{*}{$M$} & \multirow[t]{2}{*}{$(S D)$} & \multirow[t]{2}{*}{$F$} & \multirow[t]{2}{*}{$p$} & \multicolumn{3}{|c|}{ Planned Comparisons } \\
\hline & & & & & & & & & $\begin{array}{l}F \\
(1,4498)\end{array}$ & $p$ \\
\hline \multirow{13}{*}{$\begin{array}{l}\text { General } \\
\text { attitudes }\end{array}$} & Risk & Risky driving & Car drivers & -0.0059940 & $(0.88582515)$ & 0.226 & 0.798 & $C D^{\mathrm{a}}$ vs $M$ & 0.39 & 0.533 \\
\hline & & & Motorcyclists & 0.0147703 & $(0.90539943)$ & & & $(C D+M)$ & 0.10 & 0.748 \\
\hline & & & Non drivers & -0.0045228 & $(0.86679057)$ & & & vs $N D$ & & \\
\hline & Rules & Negative attitude & Car drivers & 0.0224562 & $(0.83957101)$ & 8.365 & $<0.001$ & $C D$ vs $M$ & 0.1 .21 & 0.272 \\
\hline & & toward traffic rules & Motorcyclists & 0.0575850 & $(0.88285922)$ & & & $(C D+M)$ & 16.31 & $<0.001$ \\
\hline & & & Non drivers & -0.0676216 & $(0.83288193)$ & & & vs $N D$ & & \\
\hline & Dui & Negative Attitude & Car drivers & -0.0181989 & $(0.95052577)$ & 2.726 & 0.066 & $C D$ vs $M$ & 0.15 & 0.697 \\
\hline & & toward driving under & Motorcyclists & -0.0320303 & $(0.95289707)$ & & & $(C D+M)$ & 5.43 & $<0.02$ \\
\hline & & $\begin{array}{l}\text { the effect of Drugs \& } \\
\text { Alcohol }\end{array}$ & Non drivers & 0.0438396 & $(0.92414486)$ & & & vs $N D$ & & \\
\hline & Speed & Tolerance toward & Car drivers & -0.0417259 & $(0.84250070)$ & 3.618 & $<0.05$ & $C D$ vs $M$ & 6.39 & $<0.02$ \\
\hline & & Speeding & Motorcyclists & 0.0395206 & $(0.88938679)$ & & & $(C D+M)$ & 0.40 & 0.525 \\
\hline & & & Non drivers & 0.0159199 & $(0.83650044)$ & & & vs $N D$ & & \\
\hline & & & & & & & & & $\begin{array}{l}F \\
(1,4357)\end{array}$ & $p$ \\
\hline \multirow{12}{*}{$\begin{array}{l}\text { Imagined } \\
\text { behaviour }\end{array}$} & Risk & Risky/inattentive & Car drivers & -0.0509894 & $(0.90921495)$ & 12.492 & $<0.001$ & $C D$ vs $M$ & 22.43 & $<0.001$ \\
\hline & & driving & Motorcyclists & 0.1151455 & $(0.93460161)$ & & & $(C D+M)$ & 0.4 .52 & $<0.05$ \\
\hline & & & Non drivers & -0.0293219 & $(0.89180740)$ & & & vs $N D$ & & \\
\hline & Rules & Positive attitude & Car drivers & 0.0311551 & $(0.96787650)$ & 1.493 & 0.225 & $C D$ vs $M$ & 2.21 & 0.138 \\
\hline & & toward traffic rules & Motorcyclists & -0.0223617 & $(0.93743657)$ & & & $(C D+M)$ & 0.50 & 0.478 \\
\hline & & & Non drivers & -0.0166527 & $(0.89651400)$ & & & vs $N D$ & & \\
\hline & Dui & Driving under the & Car drivers & -0.0533039 & $(0.89163424)$ & 6.317 & $<0.01$ & $C D$ vs $M$ & 12.51 & $<0.001$ \\
\hline & & effect of Drugs \& & Motorcyclists & 0.0690945 & $(0.93389186)$ & & & $(C D+M)$ & 0.00 & 0.955 \\
\hline & & Alcohol & Non drivers & 0.0062813 & $(0.87589279)$ & & & vs $N D$ & & \\
\hline & Speed & Cautious driving & Car drivers & -0.1511313 & $(0.96997772)$ & 76.209 & $<0.001$ & $C D$ vs $M$ & 3.25 & 0.138 \\
\hline & & & Motorcyclists & -0.0882487 & $(0.90674690)$ & & & $(C D+M)$ & 142.30 & $<0.001$ \\
\hline & & & Non drivers & 0.2224775 & $(0.82572982)$ & & & vs $N D$ & & \\
\hline
\end{tabular}

${ }^{\text {a }}$ Abbreviation: $C D$ Car drivers, $M$ Motorcyclists, ND Non drivers.

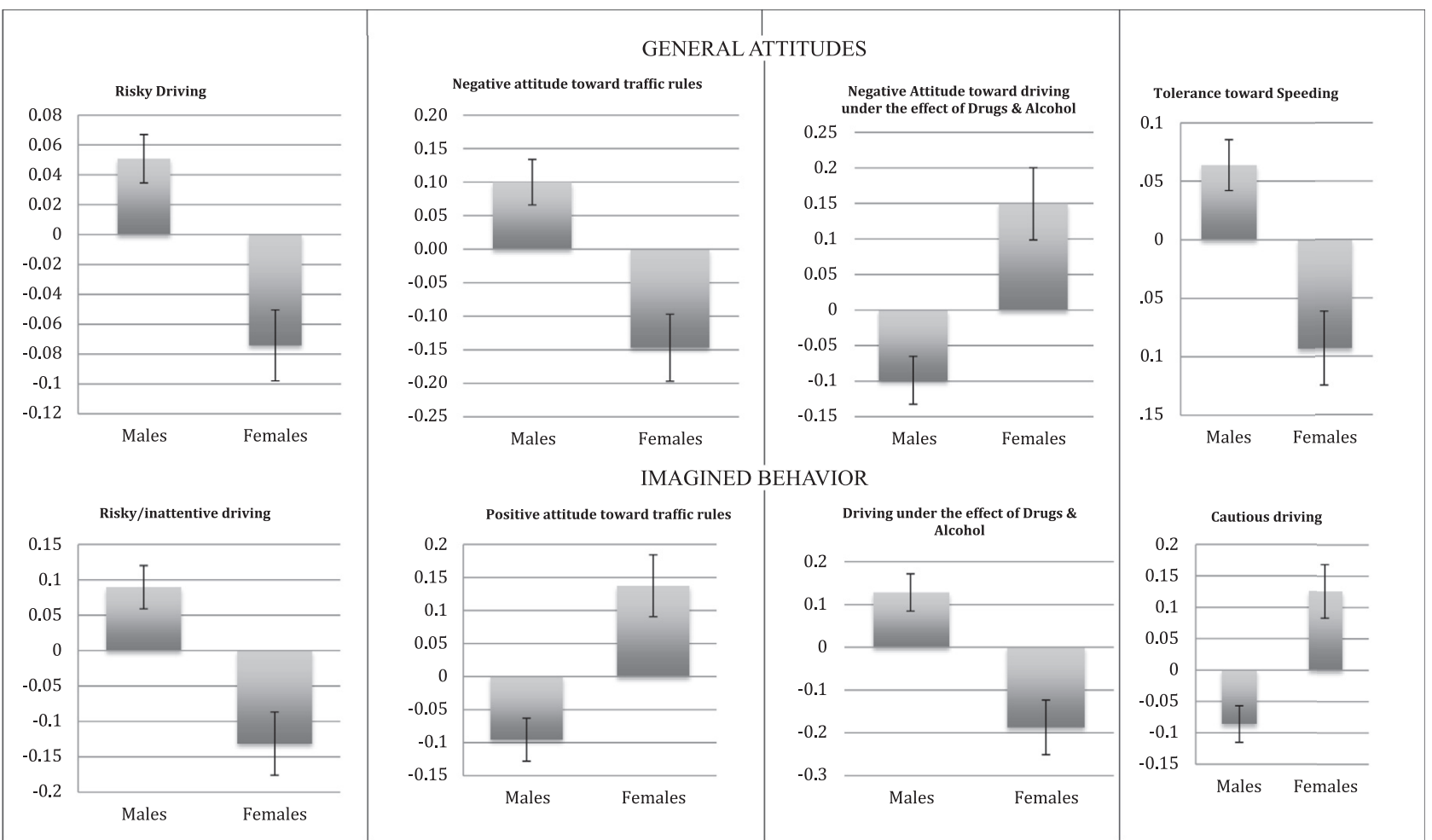

Fig. 2. Mean factor scores for the four dimensions (Risk-, Rules-, DUI-, and Speed-related factors) derived from both the Attitudes and the Imagined Behaviours Scales are represented for Gender. 
Table 6

Mean factor scores for the four dimensions (Risk, Rules, DUI, and Speed) of the Attitudes and the Imagined Behaviours Scales are represented for Gender. Standard errors are reported in brackets.

\begin{tabular}{|c|c|c|c|c|c|c|c|}
\hline & & Measure & Group & $M$ & $(S D)$ & $F(1,4494)$ & $p$ \\
\hline \multirow[t]{8}{*}{ General attitudes } & \multirow[t]{2}{*}{ Risk } & \multirow[t]{2}{*}{ Risky driving } & Males & 0.050753 & $(0.890546)$ & \multirow[t]{2}{*}{21.763} & \multirow[t]{2}{*}{$<0.001$} \\
\hline & & & Females & -0.074232 & $(0.870982)$ & & \\
\hline & \multirow[t]{2}{*}{ Rules } & \multirow[t]{2}{*}{ Negative attitude toward traffic rules } & Males & 0.099969 & $(0.859678)$ & \multirow[t]{2}{*}{93.292} & \multirow[t]{2}{*}{$<0.001$} \\
\hline & & & Females & -0.146834 & $(0.815068)$ & & \\
\hline & \multirow[t]{2}{*}{ Dui } & \multirow{2}{*}{$\begin{array}{l}\text { Negative Attitude toward driving under } \\
\text { the effect of Drugs \& Alcohol }\end{array}$} & Males & -0.098714 & $(1.013448)$ & \multirow[t]{2}{*}{76.978} & \multirow[t]{2}{*}{$<0.001$} \\
\hline & & & Females & 0.149467 & $(0.798411)$ & & \\
\hline & \multirow[t]{2}{*}{ Speed } & \multirow[t]{2}{*}{ Tolerance toward Speeding } & Males & 0.063869 & $(0.872025)$ & 36.966 & $<0.001$ \\
\hline & & & & & & $F(1,4354)$ & $P$ \\
\hline \multirow[t]{6}{*}{ Imagined behaviour } & \multirow[t]{2}{*}{ Risk } & \multirow[t]{2}{*}{ Risky/inattentive driving } & Males & 0.089471 & $(0.943154)$ & \multirow[t]{2}{*}{62.618} & \multirow[t]{2}{*}{$<0.001$} \\
\hline & & & Females & -0.131376 & $(0.848527)$ & & \\
\hline & \multirow[t]{2}{*}{ Rules } & \multirow[t]{2}{*}{ Positive attitude toward traffic rules } & Males & -0.095584 & $(0.943586)$ & \multirow[t]{2}{*}{66.362} & \multirow[t]{2}{*}{$<0.001$} \\
\hline & & & Females & 0.137439 & $(0.905570)$ & & \\
\hline & \multirow[t]{2}{*}{ Dui } & Driving under the effect of Drugs \& & Males & 0.128131 & $(0.940142)$ & \multirow[t]{2}{*}{133.822} & \multirow[t]{2}{*}{$<0.001$} \\
\hline & & Alcohol & Females & -0.187285 & $(0.798038)$ & & \\
\hline
\end{tabular}

Accident Risk Perception and Concern

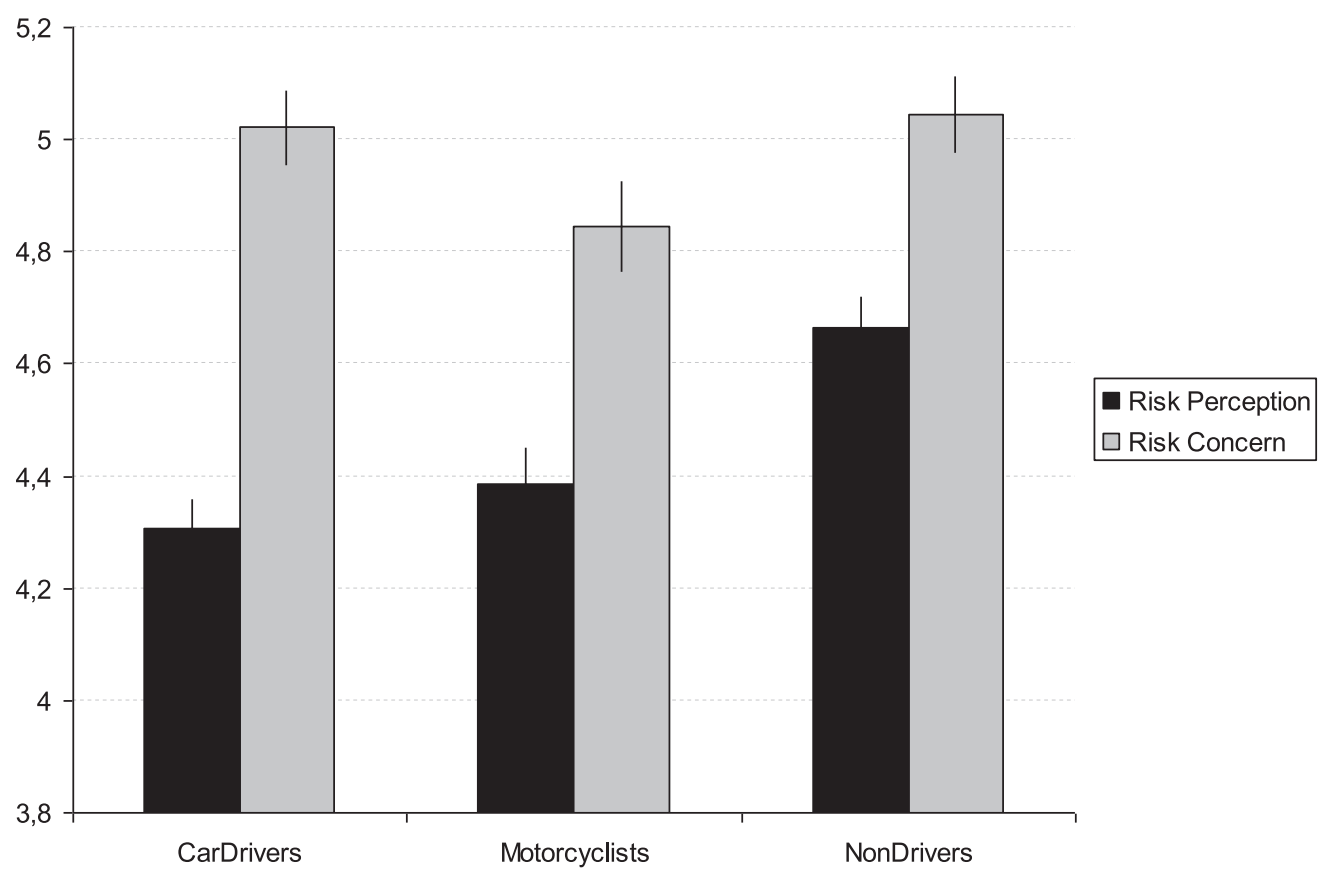

Fig. 3. Mean scores of the crash risk Perception and risk Concern are represented for each group of road users (car drivers, motorcyclists and non-drivers).

interaction $[\mathrm{F}(6,13050)=19.86 ; \mathrm{p}<.001]$, indicating that the groups show different scores trends in the four scale components (Fig. 1 and Table 5). Also Gender X Component interaction show a significant difference $([\mathrm{F}(3,13050)=86.23$; $\mathrm{p}<.001]$ (Fig. 2 and Table 6), but the interaction Group X Gender was not significant $([F(6,13050)=1.62 ; p=.197]$. Therefore, we can exclude an influence of the gender variable on the group outputs.

Planned comparisons for the Group revealed that non drivers participants had lower scores on the Risky and inattentive driving component $[\mathrm{F}(1,4357)=4.52, \mathrm{p}<.05]$, and higher scores on the Cautious driving component $[\mathrm{F}(1,4357)=142.31$, $\mathrm{p}<.001$ ] than car drivers and motorcyclists. Also, motorcycle riders had higher scores on the Risky and inattentive driving component $[\mathrm{F}(1,4357)=22.43, \mathrm{p}<.001]$ and on the Positive attitude toward drug and alcohol $[\mathrm{F}(1,4357)=12.51, \mathrm{p}<.001]$ than car drivers. The three groups did not differ in any other component ( $p>.05$ in all cases). Comparisons for the Gender revealed different effects for all IDBS Components. Precisely, females showed lower scores on Risky and inattentive driving $[F(1,4354)=62.61, \mathrm{p}<.001]$, and Positive attitude toward Drugs \&alcohol $[\mathrm{F}(1,4354)=133.822, \mathrm{p}<.001]$, while they showed higher scores on Cautious driving $[\mathrm{F}(1,4354)=56.5, \mathrm{p}<.001]$, and Positive attitude toward traffic code $[\mathrm{F}(1,4354)=66.36$, $\mathrm{p}<.001$ ]. 
Notably, the same ANOVAs were carried out on the factor scores obtained using the polichoric correlations. The results were virtually identical to those obtained using the Pearson's correlations.

\subsubsection{Crash risk perception}

Scores from the two Crash Risk Perception items were submitted to a 3x2x2 ANOVA mixed design, with Group (Cardrivers, Motorcyclists and Non-drivers) and Gender (Female and Male) as between factors, and Crash Risk (Probability and Concern) as repeated measures. We have included the gender variable to verify its effects on the outputs of the group once again.

The ANOVA showed a significant main effect of the Group $[F(1,4584)=163.38 ; \mathrm{p}<.001]$, due to non-drivers showing a higher crash risk perception than both two groups of Car-drivers and Motorcyclists, which did not differ each others on the perception of a road crash risk. Interestingly, the ANOVA also yielded a significant Group $\times$ Crash Risk interaction [F(2,4584) $=6.33 ; \mathrm{p}<.01 \mathrm{]}$, revealing that the groups show different scores trends in the two risk measures. Post hoc contrasts revealed that, while Car-drivers and Motorcyclists did not differ significantly on the level of crash risk perception, these two groups clearly show a significant difference on the level of concern about this risk, with Motorcyclists being significantly less concerned than Car-drivers about the risk of a road crash $(\mathrm{p}<.02$; Fig. 2$)$. This result is extremely interesting as it shows that, even if the crash risk perception is the same, Car-drivers and Motorcyclists differ in the level of concern about this risk, with riders being less worried than drivers. This could lead to a high probability of risky driving behaviour for Motorcyclists compared to Car-drivers. Interestingly, the results also revealed that Motorcyclists are significantly less concerned about the risk of road crashes than both Car-drivers and Non-drivers.

The ANOVA also showed a significant Gender $\times$ Crash Risk interaction $[F(1,4584)=35.74 ; \mathrm{p}<.001]$, but not for the interaction Group X Gender $[F(1,4584)=1,520 ; p=.219]$. We can exclude gender effect on the group. Comparisons for Gender revealed different effects on concern $[\mathrm{F}(1,4600)=45.41 ; \mathrm{p}=<0.001]$, with females that obtained higher scores. Differently, no gender differences were found on of crash risk perception $[F(1,4601)=0.203 ; p=652]$.

\section{Discussion}

Although the number of car crashes has gradually reduced in the last decade, the number of motorcycle crashes has remained nearly the same. As a result, young motorcyclists are over-represented in the road crash rates compared to cardrivers. For the first time, using a large sample size from six different European countries, the present study investigated whether such a discrepancy can be accounted for by differences in attitudes toward road safety issues, driving behaviours in specific imagined situations, risk perception and concern about this risk among young drivers, riders and pedestrians.

One of the main results is that there seems to be no differences in the general attitude toward the road safety issues between motorcyclists and car-drivers. Specifically, these groups show the same tendency toward violations of road rules, drugs and alcohol driving and incorrect driving behaviours, with the attitude scales showing a significant difference only in the tendency toward speed. Riders have a greater tendency to adopt a fast driving behaviour compared to drivers. This is in line with some studies suggesting that riding too fast is associated with a higher risk percentage of being involved in road crashes (e.g. Carroll \& Waller, 1980; Lin et al., 2003; Wells, 1986). Specific attitudes toward road safety issues have been also found to correlate with fast driving (Parker \& Manstead, 1996).

Notably, although the attitude scale toward road rules did not show remarkable differences between drivers and riders, these two groups significantly differ from one another when evaluating their hypothetical driving behaviours in imagined situations. Specifically, when required to imagine themselves in a specific driving situation, motorcyclists showed a higher tendency to violations of the traffic rules and driving under the influence of drugs and alcohol (DUI) compared to car drivers. This seems to support the idea, advanced in some studies, that motorcyclists are not a specific group of people that differ from the general driving population in their driving attitudes. Rather they seem to behave in different ways from other drivers in imagined driving situations.

In a study evaluating the attitudes toward road safety issues and the specific characteristics of personality from a UKsample of road users, Horswill and Helman (2003) did not found differences between motorcyclists and car drivers in driving attitudes and in general measures of behavioural intentions, such as sensation-seeking and social motives. On the other hand, they found differences in driving behaviour between these groups. In their study, the participants completed a set of tests of driving behaviour and performed a driving task in a video-based car/motorcycle simulator. Motorcyclists, car drivers and a group of both car and motorcycle drivers were assessed on behavioral measures known to relate to crash involvement. The Authors found that motorcyclists who imagined they were riding their usual motorcycle took greater risks than both the car drivers and the group of motorcyclists who imagined they were driving their usual car. Hence, people usually driving both a car and a motorcycle behave in different way according to whether they were imagined themselves in a car or on a motorcycle. This suggests that the larger risk-taking behaviors of motorcyclists appears to be a characteristic of being on a motorcycle rather than a characteristic of being a motorcyclist. The present study provides further support to this hypothesis and, most importantly, it extends these findings to the broader population of road users from six different European Countries. On these grounds, one might hypothesize that the risk-taking driving behaviours are afforded mostly by the structural features of the motorcycles compared to cars. Specifically, motorcycles are smaller, lighter, occupy less road space, are more maneuverable and faster than cars, resulting in a higher degree of directness and responsiveness (Walker, Stanton, \& 
Salmon, 2011). Each of these features might facilitate the fast-driving behaviour and speed limits violations of motorcyclists compared to car-drivers. This suggests that the road rules compliance of motorcyclists depends more on the specific driving context (e.g., the interaction between the structural features of the vehicle and the actual availability of the forbidden behavior) compared to car drivers. Present findings fit well with the predictions of the person-situation interaction theoretical model, wherein riders and drivers can be viewed as different situational roles characterized by specific driving behaviours that are mostly elicited by the specific vehicle used.

A difference between attitude and imagined driving behaviours is also observed in the use of drugs and alcohol. Specifically, we found no significant differences between the group of young car drivers and riders in the attitude toward drugs and alcohol. Rather, these two groups significantly differ as regards the use of drugs and alcohol in the imagined driving behaviour scale, with riders being more prone than drivers to alcohol and drugs consumption. This could account for the statistics on road crashes showing that motorcyclists are more likely to have consumed alcohol than are other drivers in fatal and nonfatal crashes (McLellan et al., 1993). Still, such a result seems to suggest the existence of a difference between general attitudes toward violations of road rules and the actual behaviours related to specific driving situations. Results from the attitude Scale of non-drivers show that pedestrians have less tolerance toward violations of road rules and toward the use of alcohol and drugs than both drivers and riders. This is not surprising, as one can imagine that those who do not drive can feel more the dangers resulting from infringements of the others.

A second important result concerns the risk perception. Previous studies suggested that one of the causes of the young motorcyclists crashes appears to be primarily related to the risk perception (Hosking et al., 2010). For instance, it has been shown that young people who tend to underestimate the likelihood of risk when driving, adopted careless behaviours more frequently than experienced drivers (Deery, 1999; Viano \& Ridella, 1996), such as speeding, hazardous driving and following a car without respecting the safety distance (Bina, Graziano, \& Bonino, 2006; Hartfield \& Fernandes, 2008). However, some others have suggested that the increased risk-taking behavior of motorcyclists was only likely to account for a small proportion of the difference in crash risk between motorcyclists and car drivers (Horswill \& Helman, 2003). Even more, motorcyclists crashes have been suggested to be unrelated to misjudgments about the overall risk perception (Mannering \& Grodsky, 1995). The present study helps in shedding some light on the different contribution of the risk perception to crashes risk in motorcyclists and car drivers, as the crash risk perception and the concern about this risk were both evaluated in these two groups of road users. Results indicate that the level of risk perception during driving behaviour is the same for motorcyclists and car-drivers. However, and most important, these two groups differ in the level of concern about this risk, with motorcyclists being less concerned than car-drivers about the risk of a road crash. This suggests that the main difference between these two groups is not strictly related to biases in the perceived risk probability, rather to the level of concern experienced about the consequences of the risk. This could lead to a high probability of risk driving behaviour for motorcyclists than for car-drivers.

These findings support the theoretical distinction between the risk perception, as mostly meant as a cognitive judgment (e.g., probability evaluation), and the risk-related worry, as meant as emotional reactions (e.g., concern about the risk consequences; Sjöberg, 1998). Specifically, results seem to indicate a more prominent role of the affective evaluation of risk consequences in the group with a higher rate of road crashes.

We add that in all ANOVA comparisons on road users, we wanted to evaluate the potential gender effects. Numerous studies showed the gender-related effects on road safety attitudes (Classen, Wang, Crizzle, Winter, \& Lanford, 2012), in particular in young drivers (Cordellieri et al., 2016). Although our results confirm that male young drivers are more prone to accept speeding, traffic violations and drugs and alcohol use by the driver, these effects do not significantly affect the differences among road users.

In conclusion, although the attitudes toward road safety rules seem to be similar in motorcyclists and car-drivers, these two groups differ when the road rules compliance is assessed by evaluating their driving behaviours in specific hypothetical situations, with motorcyclists being more prone then car-drivers to violations of traffic rules. Moreover, although the level of risk perception during driving behaviour is the same in motorcyclists and car-drivers, the two groups differ in the level of concern about this risk, with motorcyclists being less concerned than car-drivers about the risk of a road crash. This could led to a high probability of risky driving behaviour in motorcyclists than in car-drivers. Of course, the results and conclusions of this study are limited to the population involved, given that the sample is not too extended, therefore, inferences to other European populations of driving might be inappropriate. Our sample should be further extended. However, we believe that our study has several interesting aspects. The main implications of our research are on practical measures aimed at increasing traffic safety, in particular, a better understanding of motorcyclists' risky behaviour. Riding a motorbike is a complex task, but we believe that the only the vehicle knowledge and control is not sufficient. Effective measures targeted at motorcyclists must take into account the context in which driving is performed. Our results showed that the vehicle favours motorcyclists' risky behaviours. Effective training models targeted to the motorcyclists should consider also other driving general aspects, not only the control of vehicle, such as higher levels of the GDE matrix (Goals for Driver Education; Hatakka, Keskinen, Gregersen, Glad, \& Hernetkoski, 2002). GDE matrix is a hierarchical model on driver education and for licensing process, initially developed in the European context.

It provides a hierarchical schema of the driver's task and addresses on four different levels:

1. The first level focuses on the vehicle control skills (Vehicle control)

2. The second level is about mastering driving in specific traffic situations (Driving in traffic situations) 
3. The third level focuses on the driving context and the drivers' goals. Examples include the type of vehicle you want to drive, the trips you make, etc. (Goals and context of driving)

4. The fourth level refers to the influence of the driver's personal aspects on behaviour in driving: attitudes, emotion regulation, and cognitive processes (Goals for life and skills for living)

The European current training systems primarily focus on levels 1 and 2. Our results show clearly that for motorcyclists, it is even more necessary to focus the training on the highest levels of the GDE model.

Generally, the road safety educational courses for motorcyclists could be focused not only on the general knowledge of the vehicle and driving skills but, also to identify the nature of own behavioural tendencies, actions, own reasons, driving objectives, motives, and own emotions in different driving situation.

\section{Acknowledgements}

Data of the present study were collected for the I.C.A.R.U.S. European project (Inter-Cultural Approaches for Road Users Safety; TREN/SUB/01-2008). The ICARUS project involved fifteen European countries and aimed at developing a road safety training model shared within European countries.

\section{Appendix A. Supplementary material}

Supplementary data to this article can be found online at https://doi.org/10.1016/j.trf.2019.07.012.

\section{References}

Bina, M., Graziano, F., \& Bonino, S. (2006). Risky driving and life styles in adolescence. Accident Analysis and Prevention, 38(3), 472-481.

Carroll, C. L., \& Waller, P. (1980). Analysis of fatal and non-fatal motorcycle crashes and comparison with passenger cars. Proceedings of the international motorcycle safety conference, Maryland: 18-23 May 1980, 3, 1153-1178.

Cervone, D., \& Shoda, Y. (Eds.). (1999). The coherence of personality: Social-cognitive bases of consistency, variability, and organization. New York: Guilford Press.

Chapman, G. B., \& Coups, E. J. (2006). Emotions and preventive health behavior: Worry, regret, and influenza vaccination. Health Psychology, 25, 82-90.

Cheng, A. S. K., Ng, T. C. K., \& Lee, H. C. (2011). A comparison of the hazard perception ability of crash-involved and crash-free motorcycle riders. Accident Analysis and Prevention, 43(4), 1464-1471.

Chorlton, K., Conner, M., \& Jamson, S. (2012). Identifying the psychological determinants of risky riding: An application of an extended Theory of Planned Behaviour. Accident Analysis and Prevention, 49, 142-153.

Classen, S., Wang, Y., Crizzle, A. M., Winter, S. M., \& Lanford, D. N. (2012). Gender differences among older drivers in a comprehensive driving evaluation. Accident Analysis and Prevention, 61, 146-152.

Collins, V., Halliday, J., Warren, R., \& Williamson, R. (2000). Cancer worries, risk perceptions, and associations with interest in DNA testing and clinic satisfaction in a familial colorectal cancer clinic. Clinical Genetics, 58, 460-468.

Cordellieri, P., Baralla, F., Ferlazzo, F., Sgalla, R., Piccardi, L., \& Giannini, A. M. (2016). Gender effects in young road users on road safety attitudes, behaviors and risk perception. Frontiers in Psychology, 27(7), 1412.

Deery, H. A. (1999). Hazard and risk perception among young novice drivers. Journal of Safety Research, 30(4), $225-236$.

Easterling, D. V., \& Leventhal, H. (1989). Contribution of concrete cognition to emotion: Neutral symptoms as elicitors of worry about cancer. Journal of Applied Psychology, 74, 787-796.

Elliott, M. A. (2010). Predicting motorcyclists' intentions to speed: Effects of selected cognitions from the theory of planned behaviour, self-identity and social identity. Accident Analysis and Prevention, 42(2), 718-725.

Elliott, M. A., Baughan, C. J., \& Sexton, B. F. (2007). Errors and violations in relation to motorcyclists' crash risk. Accident Analysis and Prevention, 39(3), 491-499.

Fell, J. C., \& Nash, C. E. (1989). The nature of the alcohol problem in U.S. fatal crashes. Health Education Quarterly, 16(3), 335-343.

Foreo, C. G., Maydeu-Olivares, A., \& Gallardo-Pujol, D. (2009). Factor analysis with ordinal indicators: A Monte Carlo study comparing DWLS and ULS estimation. Structural Equation Modeling: A Multidisciplinary Journal, 16(4), 625-641.

Fox, J. (2013). Polycor package in R. Available at <http://www2.uaem.mx/rmirror/web/packages/polycor/polycor.pdf> Accessed August 24, 2018.

Harrison, W. A., \& Christie, R. (2005). Exposure survey of motorcyclists in new South Wales. Accident Analysis and Prevention, 37(3), 441-451.

Hartfield, J., \& Fernandes, R. (2008). The role of risk-propensity in the risky driving of younger driver. Accident Analysis and Preventition, 41(1), 25-35.

Hatakka, M., Keskinen, E., Gregersen, N. P., Glad, A., \& Hernetkoski, K. (2002). From control of the vehicle to personal self-control; broadening the perspectives to driver education. Transportation Research, Part F, 201-215.

Horswill, M. S., \& Helman, S. (2003). A behavioural comparison between motorcyclists and a matched group of non-motorcycling car drivers: Factors influencing crash risk. Accident Analysis and Prevention, 35(4), 589-597.

Hosking, S. G., Liu, C. C., \& Bayly, M. (2010). The visual search patterns and hazard responses of experienced and inexperienced motorcycleriders. Accident Analysis and Prevention, 42(1), 196-202.

Iversen, H., \& Rundmo, T. (2004). Attitudes towards traffic safety, driving behaviour and crash involvement among the Norwegian public. Ergonomics, 47(5), $555-572$.

Lajunen, T., Parker, D., \& Summala, H. (2004). The Manchester Driver Behaviour Questionnaire: A cross-cultural study. Accident Analysis and Prevention, 36 (2), 231-238.

Lin, M. R., Chang, S. H., Pai, L., \& Keyl, P. M. (2003). A longitudinal study of risk factors for motorcycle crashes among junior college students in Taiwan. Accident Analysis and Prevention, 35(2), 243-252.

Loewenstein, G. F., Weber, E. U., Hsee, C. K., \& Welch, N. (2001). Risk as feelings. Psychological Bulletin, 127, $267-286$.

Mannering, F. L., \& Grodsky, L. L. (1995). Statistical analysis of motorcyclists' perceived crash risk. Accident Analysis and Prevention, 27(1), 21-31.

McCaul, K. D., \& Mullens, A. B. (2003). Affect, thought, and self-protective health behavior: The case of worry and cancer screening. In J. Suls \& K. Wallston (Eds.), Social psychological foundations of health and illness (pp. 137-168). Malden, MA: Blackwell.

McLellan, B. A., Vingilis, E., Larkin, E., Studuto, G., Macartney-Fligate, M., \& Sharkey, P. W. (1993). Psychosocial characteristics and follow-up of drinking and non-drinking drivers in motor vehicle crashes. Journal of Trauma, 35(2), 245-250.

Organisation for Economic Co-operation and Development (OECD) (2006). Young. Drivers: The Road to Safety. OECD Publishing, Paris, France. Available at <http://www.oecd.org/itf/37556934.pdf> Accessed August 24, 2018. 
Özkan, T., Lajunen, T., Dogruyol, B., Yildirim, Z., \& Coymak, A. (2012). Motorcycle crashes, rider behaviour, and psychological models. Accident Analysis and Prevention, 49, 124-132.

Parker, D., Lajunen, T., \& Strandling, S. (1998). Attitudinal predictors of interpersonally aggressive violations on the road. Transportation Research Part F: Traffic Psychology and Behaviour, 1(1), 11-24.

Parker, D., \& Manstead, A. S. R. (1996). The social psychology of driver behaviour. In G. Semin \& K. Fiedler (Eds.), Applied social psychology (pp. 198-224). London: Sage.

Reason, J. T., Manstead, A., Stradling, S., \& Baxter, J. S. (1990). Errors and violations on the roads: A real distinction? Ergonomics, $33(10-11), 1315-1332$.

Rolls, G.W.P., Ingham, R. (1992). Safe and unsafe: A comparative study of younger male drivers. AA Foundation for Road Research, Basingstoke, UK. Available at <https://roadsafetyfoundation.org/wp-content/uploads/2017/11/safe-and-unsafe-a-comparative-study-of-younger-male-drivers.pdf> Accessed August 24, 2018.

Savolainen, P., \& Mannering, F. (2007). Probabilistic models of motorcyclists' injury severities in single- and multi-vehicle crashes. Accident Analysis and Prevention, 39, 955-963.

Schmiege, A. J., Klein, W. M. P., \& Bryan, A. (2009). Distinsion between worry and perceived risk in the contextr of the theory of planned behavior. Journal of Applied Social Psychology, 39(1), 95-119.

Sexton, B., Baughan, C., Elliot, M., Maycock, G. (2004). The crash risk of motorcyclists. TRL Report 607, Transport research laboratory, Crowthorne, England. Available at <https://trl.co.uk/sites/default/files/TRL607\%282\%29.pdf> Accessed August 24, 2018.

Sjöberg, L. (1998). Worry and risk perception. Risk Analysis, 18(1), 85-93.

Slovic, P., Peters, E., Finucane, M. L., \& MacGregor, D. G. (2005). Affect, risk, and decision making. Health Psychology, 24, S35-S40.

Subramanian, R. (2006). Motor vehicle traffic crashesasa leading cause of death in the United States, 2003. Traffic safety facts-research notes, National Highway Traffic Safety Administration, Washington, D.C. Available at <https://crashstats.nhtsa.dot.gov/Api/Public/ViewPublication/810568> Accessed August 24, 2018.

Tunnicliff, D. J., Watson, B. C., White, K. M., Hyde, M. K., Schonfeld, C. C., \& Wishart, D. E. (2012). Understanding the factors influencing safe and unsafe motorcycle rider intentions. Accident Analysis and Prevention, 49, 133-141.

Viano, D., \& Ridella, S. (1996). Significance of intersection crashes for older drivers. SAE Transactions, 105, 451-457.

Walker, G. H., Stanton, N. A., \& Salmon, P. M. (2011). Cognitive compatibility of Motorcyclists and Car Drivers. Accident Analysis and Prevention, 43, 878-888.

Walker, G. H., Stanton, N. A., \& Young, M. S. (2006). The ironies of vehicle feedback in car design. Ergonomics, 49(2), 161-179.

Walker, G. H., Stanton, N. A., \& Young, M. S. (2007). What's happened to car design? An exploratory study into the effect of 15 years of progress on driver situation awareness. International Journal of Vehicle Design, 45(1/2), 266-282.

Wells, P. (1986). Observations of motorcycle riders at junctions. Transport and Road Research Laboratory, Research Report 39, Crowthorne, England.

West, R., \& Hall, J. (1997). The role of personality and attitudes in traffic crash risk. Applied Psychology: An International Review, 46(3), 253-264.

World Health Organization (WHO) (2004). Preventing road traffic injury: A public health perspective for Europe. Copenhagen, WHO, Regional Office for Europe. Available at <http://www.euro.who.int/_data/assets/pdf_file/0003/87564/E82659.pdf> Accessed August $24,2018$. 